University of Nebraska - Lincoln

DigitalCommons@University of Nebraska - Lincoln

USDA National Wildlife Research Center - Staff Publications
U.S. Department of Agriculture: Animal and Plant Health Inspection Service

August 2006

\title{
A Shocking Device for Protection of Concentrated Food Sources from Black Bears
}

Stewart W. Breck

USDA/APHIS/WS National Wildlife Research Center, stewart.w.breck@aphis.usda.gov

Nathan Lance

USDA-WS-National Wildlife Research Center

Peggy Callahan

Wildlife Science Center

Follow this and additional works at: https://digitalcommons.unl.edu/icwdm_usdanwrc

Part of the Environmental Sciences Commons

Breck, Stewart W.; Lance, Nathan; and Callahan, Peggy, "A Shocking Device for Protection of Concentrated Food Sources from Black Bears" (2006). USDA National Wildlife Research Center - Staff Publications. 104. https://digitalcommons.unl.edu/icwdm_usdanwrc/104

This Article is brought to you for free and open access by the U.S. Department of Agriculture: Animal and Plant Health Inspection Service at DigitalCommons@University of Nebraska - Lincoln. It has been accepted for inclusion in USDA National Wildlife Research Center - Staff Publications by an authorized administrator of DigitalCommons@University of Nebraska - Lincoln. 


\title{
A Shocking Device for Protection of Concentrated Food Sources from Black Bears
}

\author{
STEWART W. BRECK, ${ }^{\mathbf{1}}$ USDA-WS-National Wildlife Research Center, Fort Collins, CO 80521, USA \\ NATHAN LANCE, USDA-WS-National Wildlife Research Center, Fort Collins, CO 80521, USA \\ PEGGY CALLAHAN, Wildlife Science Center, Forest Lake, MN 55025, USA
}

\begin{abstract}
Conflicts with American black bears (Ursus americanus) are increasing in rural and suburban areas throughout the United States. Human encroachment on bear range has increased availability of garbage, bird feeders, beehives, and other food sources. Preventing bears from attaining food from anthropogenic sources could mitigate these conflicts. We tested a new shocking mechanism that is being marketed to deter black bears from attaining food from clumped anthropogenic food sources. The Nuisance Bear Controller (NBC) has two 6-volt batteries wired to an automobile vibrator coil/condenser that emits 10,000-13,000 volts through a disk that triggers the device. Activation of the NBC only occurs when a bear or other animal contacts the disk. We tested the NBC in a rural area of central Minnesota by placing both unprotected and protected simulated bird feeders at 10 independent sites during summer and autumn 2004 and measuring the fate of each feeder. During the test period no protected feeders were robbed or destroyed by black bears, whereas $40 \%$ of unprotected feeders were robbed or destroyed $(\mathrm{P}=0.043$, one-tailed Fisher's exact test). The NBC is an inexpensive (\$200.00), portable, and adaptable system that potentially can be used in a variety of situations to deter bears from accessing concentrated food sources. (WILDLIFE SOCIETY BULLETIN 34(1):23-26; 2006)
\end{abstract}

\section{Key words}

black bear, human-wildlife conflict, Minnesota, nuisance bear controller, Ursus americanus.

Conflicts with black bears (Ursus americanus) in suburban-urban areas are increasing throughout many areas in the United States (LeCount 1982, Mattson 1990, Beckmann and Berger 2003, Zack et al. 2003). In some cases conflicts increase when natural food crops fail and bears seek alternative food (Costello et al. 2001, Breck unpublished data). In cases where human development occurs near black bear habitat, animals may confine most of their activity within town limits because of concentrated food sources (Beckmann and Berger 2003). In both cases the attraction to human development is reliable food sources (e.g., garbage, fruit trees, beehives, and bird seed). Bears that discover anthropogenic food are more likely to associate human development with food and may become bolder in their searches, thus becoming a public nuisance requiring additional management (Beckmann and Berger 2003). Management activities like trapping or lethal control can be expensive, time consuming, and unpopular with some residents (Loker et al. 1999, Koval and Mertig 2004). Preventing bears from attaining anthropogenic food sources may offer a cost-effective, sustainable, and socially appealing solution for reducing conflict.

Preventing bears from attaining anthropogenic food requires that sources be eliminated or protected. Elimination of food sources through the establishment of city and county ordinances and public education may offer the most hope for a long-term, sustainable solution in may urban/suburban areas that experience bear problems (Beckmann et al. 2004). However, little is known about the effectiveness of these strategies and it is likely that strategies for eliminating food sources will not work in all cases. In particular, elimination of anthropogenic food sources may be difficult if it impacts people's livelihood or hobby (e.g., feeding birds). In these cases protecting food source may be a more viable option.

Electric fencing can be a useful tool for protecting anthropogenic resources from bears (Ambrose and Sanders 1978, O'Brien and

${ }^{1}$ E-mail: stewart.w.breck@aphis.usda.gov
Marsh 1990, Stowell and Willging 1992, Huygens and Hayashi 1999). However, electric fencing may not always be appropriate due to expense, energy requirements, and problems associated with set-up and maintenance, particularly in cases where the amount of food is small (e.g., 1 or a few bee hives, a few bird feeders, or a small number of fruit trees). In these situations an inexpensive device that protects anthropogenic food sources from bears could help reduce a bear's utilization of human food, thereby reducing the amount of conflict.

We evaluated such a device (i.e., Nuisance Bear Controller, $\$ 200.00$, Ralph E. Arnold, 710 Broadway Street, Superior, Wisconsin 54880 USA) developed to protect concentrated food sources. Our objectives are to describe the NBC and provide results from field tests where we protected simulated bird feeders from black bears.

\section{Methods}

\section{Materials}

The NBC is powered by two 6-volt lantern batteries, linked in series, which are wired to a 12 -volt automobile vibrator coil and condenser. The coil/condenser is mounted and wired to a metal pipe with a metal disk (i.e., trigger plate). The trigger plate is fastened to the top of the pipe by attaching a rubber mat to the center of the trigger plate and then fastening the pipe to the rubber mat. The rubber mat insulates the trigger plate from the metal center pipe (Fig. 1). On the inside of the rubber mat and surrounding the pipe is a metal ring that is wired to the coil. When the trigger plate is moved, the metal ring contacts the center pipe and activates the NBC by completing an electrical circuit. When activated, the NBC emits between 10,000-13,000 volts; activation of the NBC only occurs when the trigger plate is moved; thus, batteries are not continuously drained. The NBC's power source can be turned on or off manually or with a timer. The NBC is easily modified to protect a variety of food sources by 


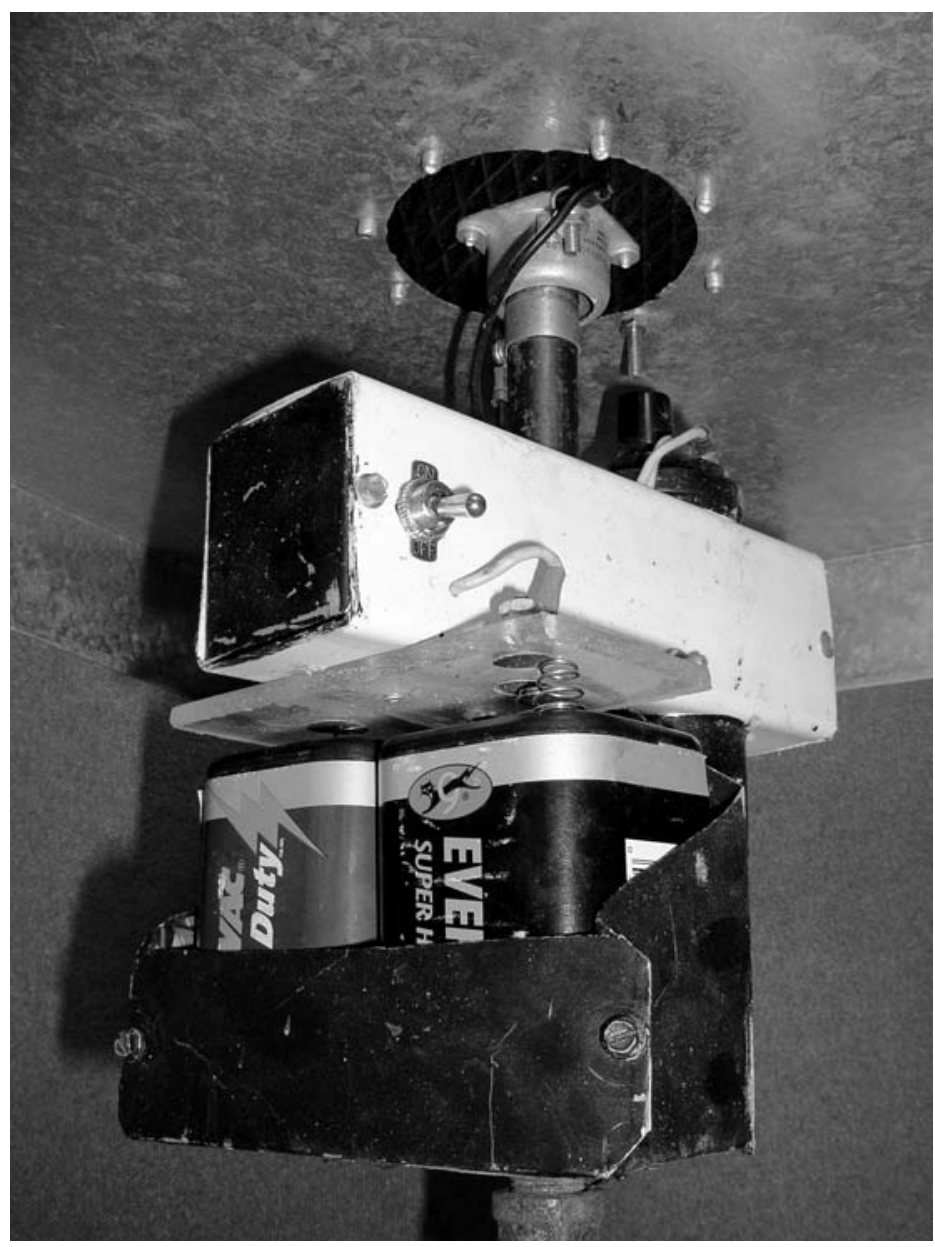

Figure 1. Underside of the Nuisance Bear Controller (NBC) showing the rubber matting attached to the trigger plate and wires running from the trigger plate to the vibrator coil/condenser. Two 6 volt batteries, linked in series, power the system but only when the trigger plate is moved up or down. Photo by N. Lance.

adjusting the shape of the trigger plate and the way the unit is mounted. For example, the trigger disk we used in this field test was originally designed for protecting bee-hives (i.e., square top that would cover the top of the hive: see Fig. 2) but we easily modified the system for protecting bird feeders. Furthermore, adjusting the thickness of the rubber mat will adjust the sensitivity of the trigger; thus, the NBC could be used to protect food from other species like skunks (Mephitis mephitis) or raccoons (Procyon lotor) by using thinner matting.

\section{Evaluating the Nuisance Bear Controller}

From 1 July-15 November 2004, we tested the durability of the NBC and its effectiveness for protecting simulated bird feeders from black bears in a rural portion of central Minnesota. The size of the study area was approximately $2,500 \mathrm{~km}^{2}$ and ranged from 30-115 km north of Minneapolis, MN. In this area, we selected 10 sites based on quality of bear habitat, the ability to access private land, and the stipulation that each site was separated by at least $30 \mathrm{~km}$ to minimize individual bears visiting multiple sites. Bear densities within the study area were unknown though statewide estimates were approximately $0.26-0.39$ bears $/ \mathrm{km}^{2}$ and bear densities within our study were believed to reflect statewide estimates (D. Pauly, Minnesota Department of Natural Resources, personal communication).

At each site we installed 2 simulated bird feeders, one protected by the NBC and the other unprotected, approximately $50 \mathrm{~m}$ from each other and monitored the fate of each device for a 4.5 month period. The simulated bird feeder was a box with 2 ends covered with $2 \times 2 \mathrm{~cm}$ mesh netting to deter small animals from attaining bait placed in the box (Fig. 2). We baited each box with sardines, liquid smoke, and bird seed and replenished baits each week. Around each station we cleared a $2 \mathrm{~m}$ diameter area for a tracking plot (Fig. 2). From 1 July-11 September we checked each simulated bird feeder every 2-3 days and, from 11 September-15 November, we checked feeders at least once a week. During each visit we determined if food was taken and whether or not the feeder was destroyed. If bait was taken or the box destroyed, we determined the cause based on presence of tracks and feces and by investigating the box for sign (i.e., tooth and claw marks). We did not replace destroyed feeders. We used a one-tailed Fisher's exact test to test for differences in the proportion of protected and unprotected boxes robbed or destroyed by black bears. All work was performed following approval by the National Wildlife Research Center's Institutional Animal Care and Use Committee under QA-872.

\section{Results}

No feeders protected by a NBC were robbed or destroyed by black bears, whereas $40 \%$ of unprotected feeders were robbed and destroyed ( $P=0.043$, one-tailed Fisher's exact test). We detected bear activity only during the first and last month of the study. During the first month, 3 unprotected feeders were destroyed and we detected bear sign near 1 protected feeder. During the last month 1 unprotected feeder was destroyed and we detected bear sign near 2 protected feeders. We detected beetles, birds, and possibly small rodents (e.g., deer mice Peromyscus maniculatus) taking bait from both protected and unprotected feeders. We detected raccoons near protected and unprotected feeders though there was no indication they attained food from either. Only $1 \mathrm{NBC}$ required maintenance and no units required a battery change during the 4.5 month trial.

\section{Discussion}

Field tests of the NBC demonstrated that the device is both effective at deterring bears and reliable in the field. In our field test the NBC protected all 10 simulated bird feeders for the 4.5 months of the study. Though our field test was conclusive, it is possible that by pairing treatments at each site we reduced the number of encounters bears had with unprotected feeders. Some bears could have encountered a protected feeder first, attained a shock, and were subsequently deterred from the unprotected feeder. On 3 separate occasions, we detected the presence of black bears in close proximity to a protected feeder, possibly indicating black bears attempted to investigate them; however, neither protected nor unprotected feeders were robbed or destroyed by bears in these instances.

Most of the bear activity we documented occurred either early or late in the study. Reasons for declining bear activity during the middle portion of our study are unknown but could be due to several factors. First, plentiful rainfall during spring and summer likely created ample natural forage that may have reduced interest in the simulated feeders. General impressions from biologists in the 


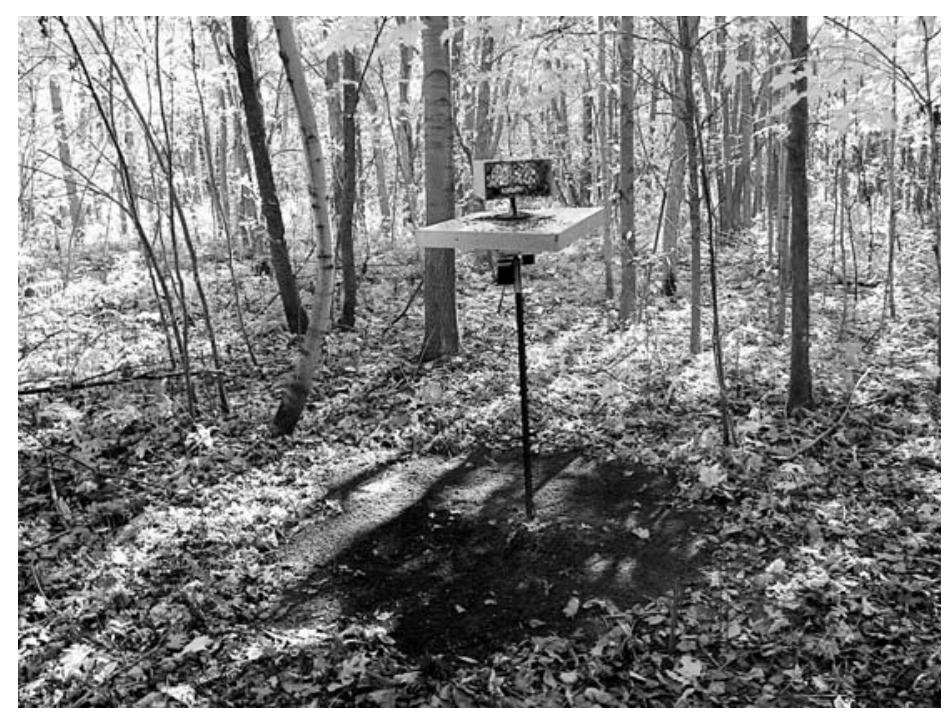

Figure 2. The Nuisance Bear Controller (NBC) postioned at a test site in central Minnesota. A simulated bird feeder sits above the square trigger plate that emits a shock when a bear or other animal moves the plate. A track plot has been cleared around the site to record the presence of animals visiting the NBC. Photo by M. Row.

area support this contention as the amount of conflict with bears in the area of our study was low compared to other years (D. Pauly, Minnesota Department of Natural Resources, personal communication). It is unknown how our results would differ during periods of natural-food scarcity, though it is likely that motivation to attain food would have been higher. Given higher motivation it is possible that bears would be more likely to overcome the NBC. Second, bear baiting and a hunting season occurred during the trials (baiting: August 13-October 17, hunting: September 1October 17). It is possible that these activities influenced the density, movement, and behavior of bears relative to our trials. Finally, it is possible that bears were more active during breeding season (June and July) and hyperphagia (autumn) and that this influenced their interaction with the simulated bird feeders.

Maintenance of the NBC was minimal. During the 4.5 -month trial, 1 unit malfunctioned because a wire disconnected, but this was easily repaired in the field. We used two 6-volt lantern batteries to power each unit, which lasted the duration of the study despite weekly testing of each system. Because of low maintenance, the NBC may be useful for protecting resources that are remote or difficult to access on a frequent basis. One potential problem with the NBC is wind, which could move the trigger plate, activate the device, and thereby drain the battery. We tested the system during a day with $30-40 \mathrm{mph}$ wind gusts and the system never activated. However, with a thinner rubber mat or with a different configuration of the trigger plate, the system may be more susceptible to wind effects.

\section{Literature Cited}

Ambrose, J. T., and O. T. Sanders. 1978. Magnitude of black bear depredation on apiaries in North Carolina. Proceedings of the Eastern Black Bear Workshop 4:167-177.

Beckmann, J. P., and J. Berger. 2003. Rapid ecological and behavioral changes in carnivores: the responses of black bears (Ursus americanus) to altered food. Journal of Zoology 261:207-212.
Though the NBC is relatively inexpensive (\$200.00/unit) compared to fencing, it could become cost prohibitive in cases when many units are needed to protect resources. In these situations it may be possible to train bears (i.e., condition them to avoid the $\mathrm{NBC}$ ), which may allow individuals experiencing bear-related problems to mimic the device on other resources and, thereby, protect the resource without actually having a device in place (i.e., Batesian mimicry), (Wickler 1968). For example, in a yard with 6 bird feeders, it may be an effective strategy to protect the 3 most vulnerable feeders and leave the other 3 unprotected but with a trigger plate attached as a way of simulating a protected feeder. We have not tested this idea with bears and the NBC but the concept supporting this idea is well documented (Wickler 1968).

The concept of the NBC (i.e., an inexpensive, adaptable shocking system that activates only when touched) is an important contribution for wildlife managers that deal with nuisance bears. However, further testing of the NBC is warranted, especially with different food sources (e.g., beehives, fruit trees, and garbage), different management scenarios (e.g., periods of natural food scarcity), and other species (e.g., grizzly bears Ursus arctos, and raccoons). Future research should incorporate more knowledge of bear movement and behavior by working with bears that are radiotagged or using cameras to better determine how animals interact with the device. Furthermore, better understanding of when to apply effort toward eliminating food sources versus protecting food sources would help managers determine which tools are most appropriate for different management scenarios. Considering the importance of eliminating versus protecting anthropogenic food sources, research evaluating the effectiveness of education or ordinances for eliminating anthropogenic food sources would aid with determining when protecting food sources is necessary.

Because of its relative low cost, adaptability, and durability, we believe the nuisance bear controller could help reduce conflict in a variety of situations and potentially with a variety of species other than black bears. As with any wildlife management tool, human safety is an important consideration and though the NBC does not emit a charge that will gravely injure a person, it does emit a powerful shock that is painful (S. Breck, personal experience). The NBC should be used with caution in areas where people (especially children) could potentially contact it. The NBC will not replace electric fencing or other similar tools but, instead, may complement them and should be integrated into the tool box for wildlife managers.

\section{Acknowledgments}

We thank D. Pauly and M. Don Carlos from the Minnesota DNR for permission to conduct this study and help with logistics, K. Beckmann and S. Vaughn who allowed access to their land, and M. Row for assistance in the field. G. Philips, K. VerCauteren and 2 anonymous reviewers provided valuable comments on the manuscript.

Beckmann, J. P., C. W. Lackey, and J. Berger. 2004. Evaluation of deterrent techniques and dogs to alter behavior of "nuisance" black bears. Wildlife Society Bulletin 32:1141-1146.

Costello, C. M., D. E. Jones, K. A. Green Hammond, R. M. Inman, K. H. Inman, B. C. Thompson, R. A. Deitner, and H. B. Quigley. 2001. A study of black bear ecology in New Mexico with models for population dynamics and 
habitat suitability. Final Report, Federal Aid in Wildlife Restoration, Project W131-R.

Huygens, O. C., and H. Hayashi. 1999. Using electric fences to reduce Asiatic black bear depredation in Nagano prefecture, central Japan. Wildlife Society Bulletin 27:959-964.

Koval, J. H., and A. G. Mertig. 2004. Attitudes of the Michigan public and wildlife agency personnel toward lethal wildlife management. Wildlife Society Bulletin 32:232-243.

LeCount, R. L. 1982. Characteristics of a central Arizona black bear population. Journal of Wildlife Management 46:861-868.

Loker, C. A., D. J. Decker, and S. J. Schwager. 1999. Social acceptability of wildlife management actions in suburban areas: 3 cases from New York. Wildlife Society Bulletin 27:152-159.

Mattson D. J. 1990. Human impacts on bear habitat use. International Conference of Bear Research and Management 8:33-56.

O'Brien, J. M., and R. E. Marsh. 1990. Vertebrate pests of beekeeping. Proceedings of the Vertebrate Pest Conference 14:228-232.

Stowell, L. R., and R. C. Willging. 1992. Bear damage to agriculture in Wisconsin. Proceedings of the Eastern Wildlife Damage Control Conference 5:96-104.

Wickler, W. 1968. Mimicry in plants and animals. World University Library, London, United Kingdom.

Zack, C. S., B. T. Milne, and W. C. Dunn. 2003. Southern oscillation index as an indicator of encounters between humans and black bears in New Mexico. Wildlife Society Bulletin 31:517-520.

Stewart Breck (below, with daughter Sage) received a B.S. and Ph.D. from Colorado State University in wildlife ecology and an M.S. from University of Nevada Reno in biology. His work includes ecological research on the role of herbivores in community and ecosystem dynamics and the management of endangered carnivores. Currently Stewart is working as a research wildlife

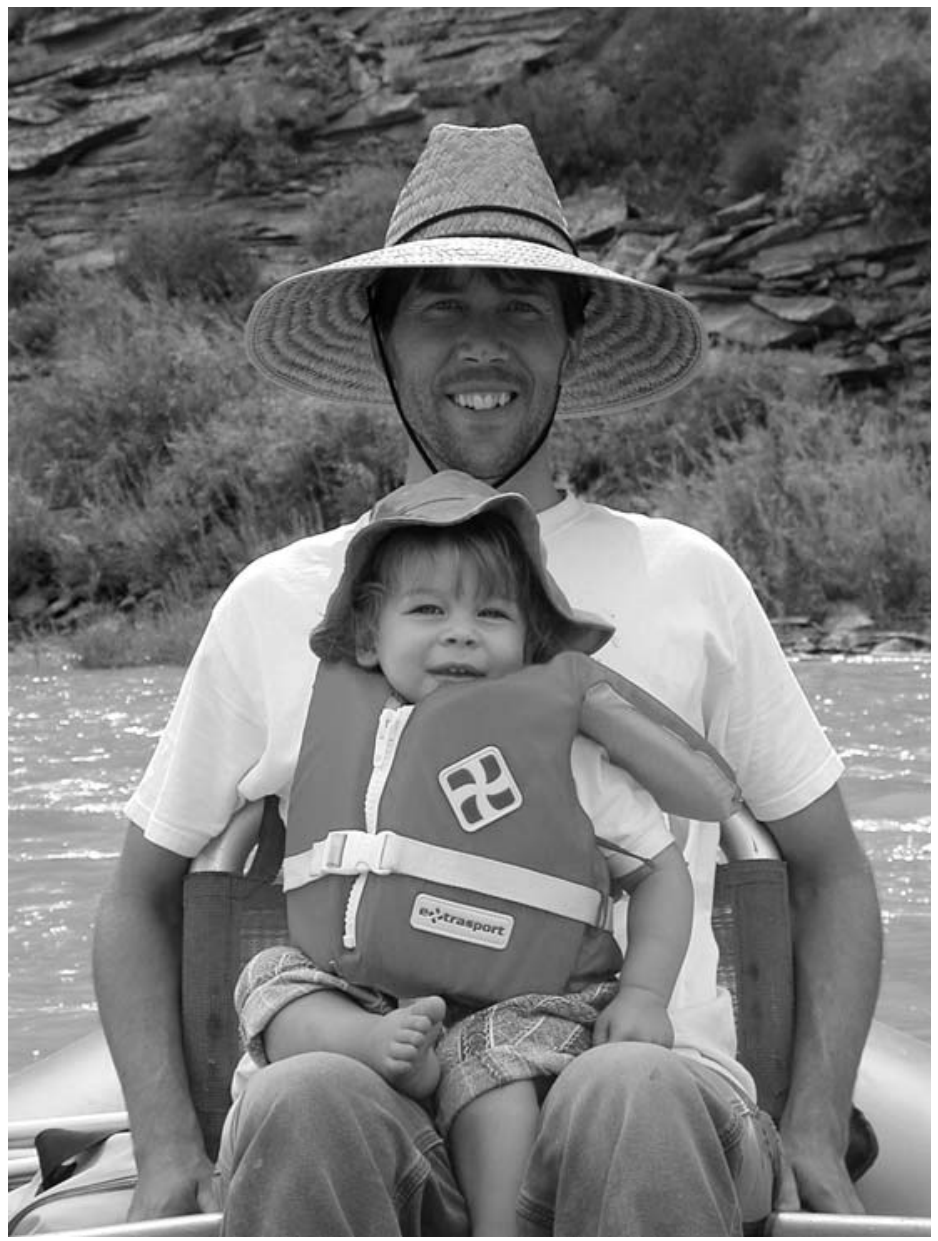

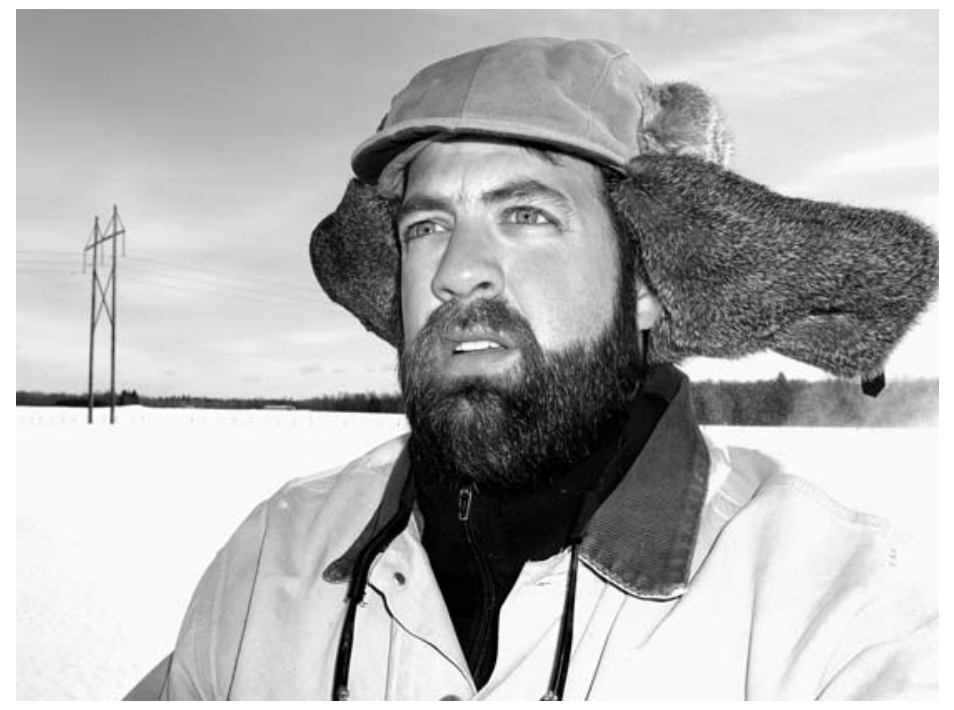

biologist for USDA-WS-National Wildlife Research Center and his research is focused on carnivore ecology and minimizing conflict between carnivores and humans. Nathan Lance (above) is a biological technician with the USDAWS/National Wildlife Research Center. He received his B.S. in wildlife biology from the University of Montana. His research interests are in humanwildlife conflicts and developing knowledge of the ecology and social context in which these problems exist. Current studies have focused on predator behavior, primarily testing control methods for large carnivores. Peggy Calahan (below) is the founder and executive director of the Wildlife Science Center. The Center's mission is to serve as an educational resource, advance understanding of wild animal biology, and provide unique scientific and technical training for wildlife agencies.

Associate editor: Applegate.

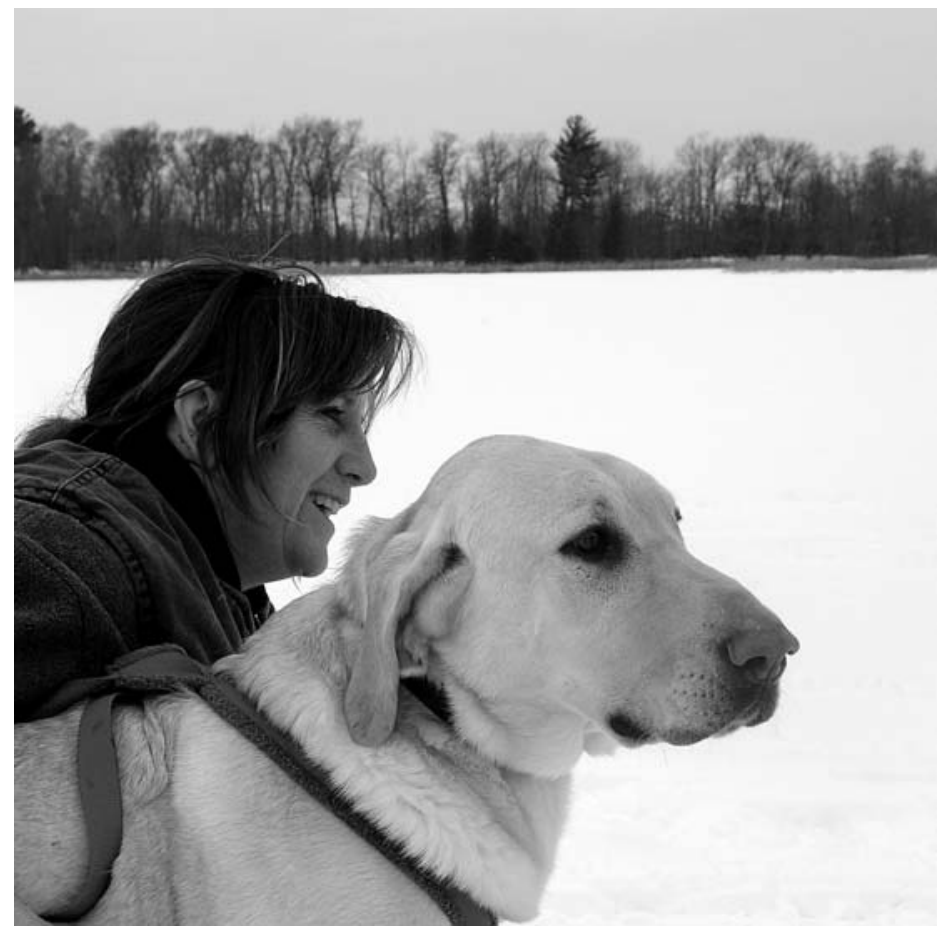

